\title{
Exergetic Investigation of a R1234yf Automotive Air Conditioning System with Internal Heat Exchanger
}

\author{
M. Direk*, M.S. Mert, F. Yüksel, A. Keleşoğlu \\ Energy Systems Engineering Department, Yalova University, Yalova, 77200, Turkey \\ E-mail: mehmet.direk@yalova.edu.tr
}

Received 23 November 2017, Revised 04 April 2018, Accepted 09 April 2018

\begin{abstract}
This experimental study presents the exergetic investigation of an automotive air conditioning (AAC) system with the refrigerant R1234yf. The air-conditioning system is based on the conventional mechanical compression refrigeration cycle. An internal heat exchanger (IHX) has been added to the system in order to provide performance enhancement. The influence of the IHX was investigated at different compressor speeds and air stream temperatures. Experimental measurements were controlled by using a data-acquisition system. The exergy destruction, exergy efficiency and the total exergy destruction per cooling capacity were calculated. The analysis results were compared with a baseline system which operates with the refrigerant R134a. Furthermore, an empirical correlation was proposed for the determination of the total exergy destruction per cooling capacity for various compressor speeds for evaluating the system performance. The exergetic efficiency of the system was improved by introducing IHX. Moreover, it was observed that the temperature rise in the air stream decreased the exergy efficiency and increased the total exergy destruction per cooling capacity.
\end{abstract}

\section{Keywords: Automobile air conditioning; exergy analysis; internal heat exchanger; R1234yf.}

\section{Introduction}

As of today, R134a is the most widely preferred refrigerant in the AAC systems. It has zero ozone depletion potential value, however, its Global Warming Potential (GWP) value is relatively high as 1430 [1]. Therefore, the usage of R134a in the new AAC systems was constrained by the European Parliament mobile air conditioning (MAC) Directive No 40/2006 [2]. According to the European Commission Regulation No 517/2014, the MAC Directive reconsidered and the applications of R134a in MAC systems will be prohibited as of 2022 [3]. Thus, it became necessary to find an alternative refrigerant to the refrigerant R134a.

Recent studies show that R1234yf is the most promising alternative refrigerant among the new low GWP refrigerants due to toxicity, flammability and its closer thermo-physical properties to R134a [4, 5]. As an advantage, R1234yf can be used without any modification in an AAC system designed for R134a [6]. However, the latent heat of vaporization for $\mathrm{R} 1234 \mathrm{yf}$ is $21-28 \%$ lower than $\mathrm{R} 134 \mathrm{a}$ at the same saturation temperatures [7]. That is the main reason for the cooling capacity and COP decreases up to $13 \%$ when R1234yf is alternatively used in the AAC system instead of R134a [8, 9, 10]. On the other hand, the performance of the system operating with R1234yf can be improved by utilizing an IHX $[11,12,13,14,15]$. The performance analysis of a system can be done by using the exergy method besides the energy conservation law. Thus, the occurring irreversibilities of each component and its amounts can be better determined for the considered system via using exergy analysis. [16, 17]. Devecioglu et al. [18] extensively studied the effect of the using plate type IHX on the liquid line of the system with $\mathrm{R} 453 \mathrm{a}$ as an option to R22. It was found that the COP obtained with R453a is lower than that of R22, but with the use of the heat exchanger, a significant improvement occurred in the COP value. They implied that the second law efficiency of the system with R22 is higher than R453a. However, they found that with IHX, the second law efficiency is enhanced by $30 \%$ for R453a [18]. Ratts and Brown [19] found that the thermal losses of compressor are increased with increasing compressor speed due to reducing isentropic efficiency of the compressor. Besides, the charge amount of the refrigerant has an influence on the volumetric efficiency of the compressor. However, it is difficult to determine the exact effect of the vehicle due to fluctuations in those values. It can be obtained by achieving steady-state conditions where the aforementioned efficiencies are constant. Thus, the performance of the system can be enhanced by increasing the compressor speed. Yataganbaba et al. [20] developed a thermodynamic model to determine the exergetic performance of the vapor compression refrigeration system with R1234yf and R1234ze as alternatives to R134a. They determined that the total exergy destruction of the system tends to increase with increasing condensation temperature. Additionally, they found that the second law efficiency of the system with R1234ze and R134a is higher than that of R1234yf. Golzari et al. [21] developed a simulation model to determine the steady-state performance of an AAC system that uses R1234yf as an alternative to R134a by applying the second law of thermodynamics. As a result of their simulation, the highest exergy destruction occurred in the compressor and the exergy efficiency of the system is higher for the R1234yf in comparison with R134a. Suhermanto et al. [22] performed an exergy analysis for an AAC system using R1234yf and $\mathrm{R} 134 \mathrm{a}$ by altering the air stream temperature. They observed that the exergy destruction increases with increasing air 
stream temperature at the inlet of the condenser channel. On the other hand, the changes in exergy destruction are more considerable for R1234yf than R134a. In addition, they observed that the most substantial exergy destruction had occurred in the compressor and the condenser. Cho et al. [23] tested an AAC system to determine the performance parameters with IHX in the case of using R1234yf instead of $\mathrm{R} 134 \mathrm{a}$ at different compressor speeds. They observed that without IHX, the performance parameters of the system are inadequate as compared to R134a; however, when the IHX adapted to the system, significant improvement occurred. On the other hand, they showed that the highest exergy destruction rate is calculated for the evaporator in the case of higher compressor speeds. For lower compressor speeds, the highest exergy destruction is witnessed in the compressor. They concluded that the total exergy destruction rate is higher in all experimental conditions for R1234yf, but with the IHX a considerable reduction is observed. On the other hand, the performance of a system can be predicted by using an empirical correlation without an experimental study. Pérez-García et al. [24] carried out a study in order to investigate a mobile air conditioning system involving an IHX with low GWP refrigerants namely R152a, R1234yf and R1234ze. The second law efficiency cycle versus IHX effectiveness and entropy production in IHX as a function of effectiveness were obtained, and It was found that the maximum entropy production occurs at an effectiveness of $66 \%$ for both R152a and R134a, whereas for the cases of R1234yf and R1234ze occurs at 55\%. Direk et al. [25] experimentally studied the effect of IHX for an AAC system with R1234yf under different compressor speeds. They observed that the rate of increase for cooling capacity is increased by employing IHX in the system under increasing compressor speed. Their results implied that the cooling capacity and COP are increased up to $7.9 \%$ and $4.1 \%$, respectively. In another study of Direk and Kelesoglu [26], performance of an AAC system including an IHX was conducted based on comparing different condensation and evaporation temperatures of R1234yf. It was concluded that the use of IHX has enhanced COP and declined exergy destruction per cooling capacity by $4 \%-6 \%$ and $13 \%-16 \%$, respectively. Qi [27] developed a new empirical correlation for the refrigerant pressure drop of a MAC evaporator employed R134a and R1234yf. They implied that data taken from experiment agreed well with predicted data. They found that deviations were $18.7 \%$ and $11.9 \%$ for R134a and R1234yf, respectively. Aral et al. [28] developed an empirical correlation to predict the performance of the AAC system using R134a and R1234yf. They used air stream temperature and the relative humidity of air at the inlet of evaporator and condenser as input parameters to generate the empirical correlation. Moreover, they conduct experiments to determine the accuracy of the results of empirical correlation. Their findings showed that the result of experiments and empirical correlations are quite similar with the mean relative error between $1.67 \%-3.01 \%$. When literature concerning R1234yf is examined, it is understood that the system performance can be improved by using IHX.

In this study, exergy analysis of the AAC system was performed to determine the locations and the levels of the irreversibilities in order to enhance the performance of the system. The exergy analysis was applied with and without IHX at different air stream temperatures and different compressor speeds. Furthermore, an empirical correlation, which provides predicting the total exergy destruction per cooling capacity, was proposed to determine the performance of the considered AAC system. Finally, the results obtained with R1234yf were compared with the base system operating with R134a.

\section{Experimental Setup}

The system consists of a conventional mechanical compression refrigeration system with the components that are used in automobiles (Figure 1). These components are a belt-driven compressor, a parallel flow condenser, a laminar microchannel evaporator, a thermostatic expansion valve (TXV), a liquid tank, a filter and a dryer. Figure 2 shows schematic view of the refrigeration system and investigated cycles. The evaporator and the condenser were located at the exit cross sections of two individual air channels each of which has a length of 1 meter. Furthermore, a $900 \mathrm{~mm}$ length double-pipe heat exchanger (IHX) was connected to the evaporator and condenser outlets. In order to provide the desired airflow in the air channels, radial fans were installed at each channel. Additionally, electric heaters were used to provide the desired airflow temperatures in the channels. For this purpose, $5 \mathrm{~kW}$ and $2 \mathrm{~kW}$ resistance heaters were mounted at the condenser and evaporator side, respectively. The cross sections of the evaporator and condenser air channels are $0.24 \times 0.24 \mathrm{~m}^{2}$ and $0.67 \times 0.35 \mathrm{~m}^{2}$, respectively.

The pipes and fittings used in the system are fully insulated against the external influences. The pipe diameters are 5/8" (15.875 $\mathrm{mm})$ and 3/8" (9.525 $\mathrm{mm})$ for the vapor and liquid lines, respectively.

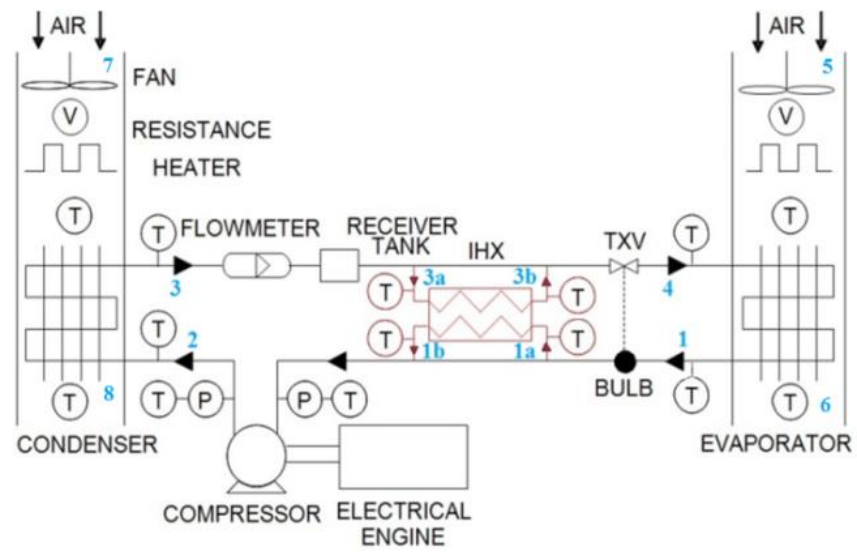

Figure 1. Experimental AAC system.
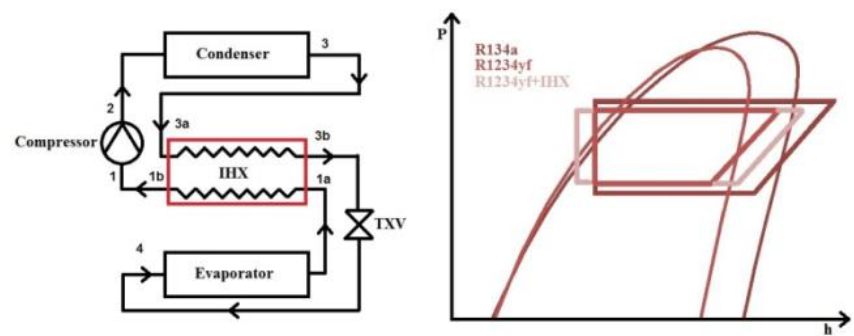

Figure 2. Schematic view of the experimental AAC system and related $P$ - $h$ diagrams.

The characteristics of the components in the experimental system are given in Table 1 . The refrigerant temperatures at various points on the system were measured with type $\mathrm{K}(\mathrm{NiCr}-\mathrm{Ni})$ thermocouples and recorded into a computer via a data acquisition system. The volume flow rate of the refrigerant was measured by a turbine type flow meter 
which was connected to the liquid line. In addition, the vaporization and condensation pressures of the refrigerant were measured by a digital manifold. Table 2 shows the range and uncertainty of the measuring devices.

Table 1. Specifications of the experimental AAC system.

\begin{tabular}{ll}
\hline Component & Specification \\
\hline \multirow{3}{*}{ Compressor } & Stroke volume: $138 \mathrm{cc}$ \\
& Cylinder numbers: 7 \\
& Max. speed: $5000 \mathrm{rpm}$ \\
\hline \multirow{3}{*}{ Condenser } & Capacity: $5.34 \mathrm{~kW}$ \\
& Dimensions: $635 \times 355 \times 20 \mathrm{~mm}^{3}$ \\
& No. of channels: 31 \\
\hline \multirow{3}{*}{ Evaporator } & Capacity: $5.23 \mathrm{~kW}$ \\
& Dimensions: $210 \times 275 \times 70 \mathrm{~mm}^{3}$ \\
& No. of channels: 20 \\
\hline
\end{tabular}

Table 2. Characteristics of the measuring instruments.

\begin{tabular}{llll}
\hline Variable & Instrument & Range & $\begin{array}{l}\text { Uncertaint } \\
\mathrm{y}\end{array}$ \\
\hline Temperature & K-type thermocouple & $0-500\left[{ }^{\circ} \mathrm{C}\right]$ & \pm 0.5 \\
Pressure & Digital manifold & $0-40[\mathrm{bar}]$ & \pm 0.75 \\
Humidity & Hygrometer & $10-100[\%]$ & \pm 3 \\
Air Velocity & Anemometer & $0.1-20[\mathrm{~m} / \mathrm{s}]$ & \pm 2 \\
Volume Flow & Turbine flow meter & $0.2-1.2\left[\mathrm{~m}^{3} / \mathrm{s}\right]$ & \pm 1 \\
Rate & & & \\
\hline
\end{tabular}

\section{Testing Process}

The experimental AAC system was first charged with $\mathrm{R} 134 \mathrm{a}$ and operated without IHX. The charge amount of $\mathrm{R} 134 \mathrm{a}$ was adjusted based on the best COP value of the system. The refrigerant R1234yf was used to obtain the influence of IHX. The refrigerant R1234yf was charged to the system considering the liquid density at the system pressure with R134a as explained in Ref [13]. In the experiments, air was supplied with $0.501 \mathrm{~m}^{3} / \mathrm{s}$ volumetric flow rate to the condenser channel. The fan connected to the evaporator channel was operated at the maximum speeds with fixed $0.147 \mathrm{~m}^{3} / \mathrm{s}$ volumetric flow rate. The volumetric flow rates were calculated with respect to the measured air stream velocities at the exits and cross sections of the each channel. Air stream temperature at the evaporator and condenser channels were fixed at $27^{\circ} \mathrm{C}$ and $35^{\circ} \mathrm{C}$ with relative humidity values between $45-60 \%$. Then, the compressor speed was increased from 1000 to $2000 \mathrm{rpm}$ with $250 \mathrm{rpm}$ speed steps. It is assumed that the system has reached the steady-state when the measured air stream temperatures vary between $\pm 0.5{ }^{\circ} \mathrm{C}$. Experiments were continued for an additional 5 minutes to make sure that the steady-state processes were reached.

\section{Thermodynamic Analysis}

The mass, energy and exergy equations were developed for the thermodynamic analysis of the system based on the first and second law of thermodynamics. The reference states are $T_{0}=298.15 \mathrm{~K}$ and $P_{0}=1 \mathrm{~atm}$. For steady state process, the mass balance equation can be expressed as follows:

$\sum \dot{m}_{i}=\sum \dot{m}_{o}$

Here, $\mathrm{m}$ " is the mass flow rate, and the subscripts " $\mathrm{i}$ " and "o" denotes the inlet and outlet streams, respectively. When the other energy effects neglected, then the following equations can be written for steady state conditions based on the energy conservation law as follows:

$0=\dot{Q}_{C V}-\dot{W}_{C V}+\sum \dot{m}_{i} h_{i}-\sum \dot{m}_{o} h_{o}$

$\dot{W}_{\text {comp }}=\dot{m}_{r}\left(h_{2}-h_{1}\right)$

$\dot{Q}_{\text {evap }}=\dot{m}_{r}\left(h_{1}-h_{4}\right)$

$C O P=\dot{Q}_{\text {evap }} / \dot{W}_{\text {comp }}$

$\dot{Q}_{\text {cond }}=\dot{m}_{r}\left(h_{2}-h_{3}\right)$

Based on the second law of thermodynamics, the specific flow exergy $\left(e_{x}\right)$ of the refrigerant is calculated as follows:

$e_{x}=\left(h-h_{0}\right)-T_{0}\left(s-s_{0}\right)$

where $h$ is the specific enthalpy, $s$ is the specific entropy, and the subscript zero denotes the reference state properties at $P_{0}$ and $T_{0}$.

Exergy loss is the exergy transfer to the outside of the system which is wasted by heat transfer to environment. Besides, exergy destruction is also a kind of thermodynamic loss that is related with the irreversibilities occurring within the system [29,30,31]. When the system is in a thermal equilibrium, then the exergy loss is zero, and the total inefficiencies contain solely of exergy destruction. In other words, the losses caused by heat transfer from the system to the environment are included within the exergy destruction $[29,30,31]$. The equipment of the AAC system is fully insulated against the external influences. The exergy destructions for the overall system $\left(\dot{E} x_{\mathrm{d}, \mathrm{sys}}\right)$, compressor ( $\left.\dot{E} x_{\mathrm{d}, \mathrm{comp}}\right)$, thermostatic expansion valve ( $\left.\dot{E} x_{\mathrm{d}, \mathrm{TXV}}\right)$, evaporator ( $\left.\dot{E} x_{\mathrm{d} \text {,evap }}\right)$, condenser $\left(\dot{E} x_{\mathrm{d}, \text { cond }}\right)$, and the internal heat exchanger $\left(\dot{E} x_{\mathrm{d}, \mathrm{IHX}}\right)$ may be determined for steady state conditions as follows:

$0=\sum \dot{Q}\left(1-\frac{T_{0}}{T}\right)-\sum \dot{W}+\sum\left(\dot{m} e_{x}\right)_{i}-\left(\dot{m} e_{x}\right)_{o}-\dot{E} x_{d, s y s}$

$\dot{E} x_{d, \text { comp }}=\dot{m}_{r}\left(e_{x 1}-e_{x 2}\right)+\dot{W}_{c o m p}$

$\dot{E} x_{d, T X V}=\dot{m}_{r}\left(e_{x 3}-e_{x 4}\right)$

$\dot{E} x_{d, \text { evap }}=\dot{m}_{r}\left(e_{x 1}-e_{x 4}\right)+\dot{m}_{a 1}\left(e_{x 5}-e_{x 6}\right)$

$\dot{E} x_{d, \text { cond }}=\dot{m}_{r}\left(e_{x 2}-e_{x 3}\right)+\dot{m}_{a 2}\left(e_{x 8}-e_{x 7}\right)$

$\dot{E} x_{d, I H X}=\dot{m}_{r}\left(e_{x 1 b}-e_{x 1 a}\right)+\dot{m}_{r}\left(e_{x 3 a}-e_{x 3 b}\right)$

$\dot{E} x_{d, t o t}=\dot{E} x_{d, \text { comp }}+\dot{E} x_{d, \text { cond }}+\dot{E} x_{d, T X V}+\dot{E} x_{d, \text { evap }}$ $+\dot{E} x_{d, I H X}$ [20]:

The exergetic efficiency can be calculated from Eq.15

$\eta_{\text {ex }}=\frac{\dot{E} x_{\text {gain }}}{\dot{E} x_{\text {pay }}}=\frac{\dot{Q}_{\text {evap }}\left(1-\frac{T_{0}}{T_{e}}\right)}{\dot{m}_{r}\left(h_{2}-h_{1}\right)}=\operatorname{COP}\left(1-\frac{T_{0}}{T_{e}}\right)$ 
where $\dot{E} x_{\text {gain }}$ is exergy increase in the evaporator and $\dot{E} x_{\text {pay }}$ is the compressor power.

$\dot{E} x_{d, R e l}=\frac{\dot{E} x_{d, c}}{\dot{E} x_{d, t o t}} 100$

Here, $\dot{E} x_{\mathrm{d}, \mathrm{c}}$ denotes the exergy destruction for each component.

The empirical correlation was developed by using the Stoecker's formula for the experimental data [32] The correlation can be expressed as Eq.17:

$\frac{\dot{E} x_{d, t}}{\dot{Q}_{\text {evap }}}=c_{1}+c_{2} T_{e}+c_{3} T_{c o}+c_{4} R P M+c_{5} T_{e}{ }^{2}+c_{6} T_{c o}{ }^{2}+$

$c_{7} R P M^{2}+c_{8} T_{e}{ }^{2} T_{c o}+c_{9} T_{e}{ }^{2} R P M+c_{10} T_{c o}{ }^{2} R P M+$

$c_{11} T_{c o}{ }^{2} T_{e}+c_{12} R P M^{2} T_{e}+c_{13} R P M^{2} T_{c o}+c_{14} T_{e}{ }^{2} T_{c o}{ }^{2} R P M$

Here, $c_{1}$ to $c_{14}$ are the coefficients of the empirical equation, RPM is the compressor speed in rpm and $T_{\mathrm{e}}$ and $T_{\text {co }}$ are the evaporation and condensation temperature of the refrigerants. The empirical correlation, which provides predicting the total exergy destruction per cooling capacity, was obtained for determining the performance of the considered AAC system without further experiments.

\section{Results and Discussion}

The results obtained from the operation with the refrigerants namely; R134a, R1234yf and R1234yf+IHX is evaluated. The exergy destruction of each component, total exergy destruction per cooling capacity and the exergy efficiency of the system under different air stream temperatures and compressor speeds are discussed.

Figure 3 demonstrates the effect of compressor speed on the relative exergy destruction when the air stream temperatures are constant at $27^{\circ} \mathrm{C}$. Increasing compressor speed causes an increase in the mass flow rate of the refrigerant. Besides that, the pressure difference of the system increases with increasing compressor speed due to decreasing evaporation and increasing condensation pressures. Thus, the entropy generation of the compressor increases. Consequently, the exergy destruction of the compressor increases.

Figure $3 \mathrm{a}$ shows the variation in relative exergy destruction of the system with R134a. At $1000 \mathrm{rpm}$, the exergy destruction of the condenser is $36 \%$ of the total exergy destruction, while the evaporator, compressor, and TXV are $31 \%, 28 \%$, and $5 \%$, respectively. The exergy destruction of the components increases with increasing compressor speed. However, the increase rate for the compressor is higher than that of the evaporator. Therefore, the exergy destruction within the compressor is higher than the other components when the compressor speed is higher than the $1250 \mathrm{rpm}$. The exergy destruction within the condenser gradually decreases while the compressor speeds increases. On the other hand, the exergy destruction of the TXV remains nearly constant for all compressor speeds.

The relative exergy destruction of the AAC system components with R1234yf is illustrated in Figure 3b. At $1000 \mathrm{rpm}$, the relative exergy destruction of the compressor, condenser, evaporator and TXV of the total exergy destruction are $36 \%, 28 \%, 29 \%$ and $7 \%$, respectively. The exergy destruction of the condenser and TXV did not change significantly, while the evaporator decreased and the compressor increased with respect to the increasing compressor speed. On the other hand, the condenser and TXV are approximately $3 \%$ and $1 \%$ higher than that of $\mathrm{R} 134 \mathrm{a}$. This is due to the lower evaporator exergy destruction that occurred for the R1234yf.

Figure $3 c$ demonstrates the variation of relative exergy destruction for the components with R2134yf+IHX. At 1000 $\mathrm{rpm}$, the relative exergy destruction of the compressor, condenser, evaporator, TXV and IHX of the total exergy destruction are $38 \%, 8 \%, 37 \%, 12 \%$ and $6 \%$, respectively. It is seen that the relative exergy destruction for the evaporator rapidly decreases with increasing compressor speed, while the TXV decreases gradually. Conversely, the relative exergy destruction for the condenser sharply increases due to increasing subcooling and superheat degree supplied from the IHX. Similarly, the relative exergy destruction values of the compressor nearly remain constant as observed for without IHX condition. Among all operating conditions, the average exergy destruction was calculated as $2.34 \mathrm{~kW}$ for the system with R134a, followed by R1234yf, with an average exergy destruction of $2.12 \mathrm{~kW}$. Since the system became more stable by the addition of IHX, the minimum exergy destruction was obtained for R1234yf + IHX as $2.07 \mathrm{~kW}$.

Figure 4 shows the relative exergy destruction of the components in the system when the air stream temperatures are $35^{\circ} \mathrm{C}$. It is understood from the figures that the sequence of the components did not change while the total exergy destruction of the system was increased. However, the exergy destruction of the evaporator decreased considerably while the other components were increased. Moreover, the total exergy destruction of the system increased with increasing air stream temperatures caused by the increasing temperature difference between refrigerant and air stream in the evaporator and the condenser.

Figure 5 illustrates the variation of total exergy destruction per cooling capacity $\dot{\mathrm{E}} \mathrm{x}_{\mathrm{d}, \text { tot }} / \dot{\mathrm{Q}}_{\mathrm{evap}}$ based on the results obtained from the empirical correlation and the experiments.

The experiments demonstrated that the cooling capacity of the system increases with increasing compressor speed due to the increasing refrigerant mass flow rate and enthalpy difference in the evaporator. Moreover, the cooling capacity of R134a is higher than that of R1234yf and R1234yf+IHX. Additionally, the total exergy destruction increases for all operating conditions because of the increasing compressor power and irreversibilities in all components of the AAC system. Furthermore, it was observed that the results obtained from the empirical correlations are in a good agreement with those obtained from the experiments. For that reason, in all operating conditions, the deviation did not exceed $8.8 \%$ between the results.

In addition, the maximum and minimum deviation was observed for the R1234yf+IHX and R1234yf as 8.8\% and $7.21 \%$, respectively. Furthermore, the increase rate of the total exergy destruction is higher than the cooling capacity. Thus, the total exergy destruction per cooling capacity increases with increasing compressor speed. For instance, at $1000 \mathrm{rpm}$ the total exergy destruction per cooling capacity is $6.29 \%, 6.38 \%$ and $5.74 \%$ for R134a, R1234yf and R1234yf+IHX, respectively. However, at $2000 \mathrm{rpm}$ that ratio is $12.94 \%, 14.42 \%$ and $12.55 \%$. The cooling capacity increases with IHX due to an increasing subcooling degree. Total exergy destruction per cooling capacity decreases when an IHX is added to the system with R1234yf. 


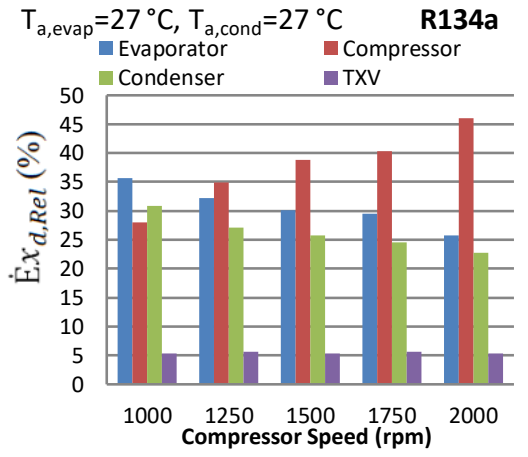

(a)

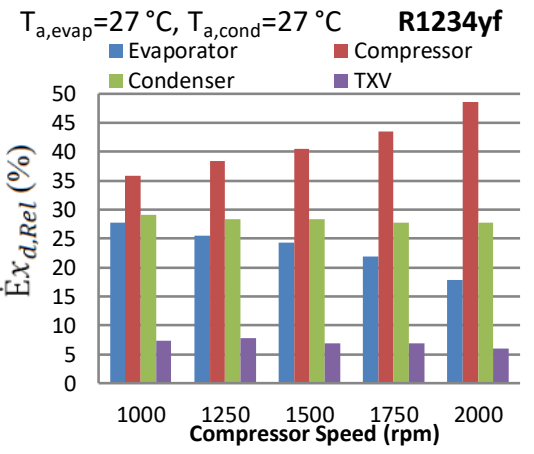

(b)

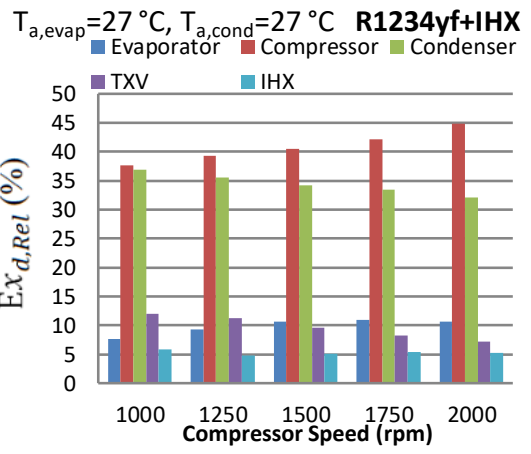

(c)

Figure 3. Exergy destruction of each component against compressor speed at the air stream temperature $27^{\circ} \mathrm{C}$ for (a) R134a, (b) R1234yf, (c) R1234yf $+I H X$.

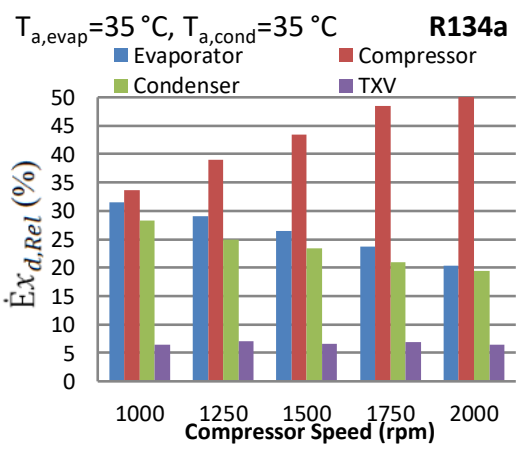

(a)

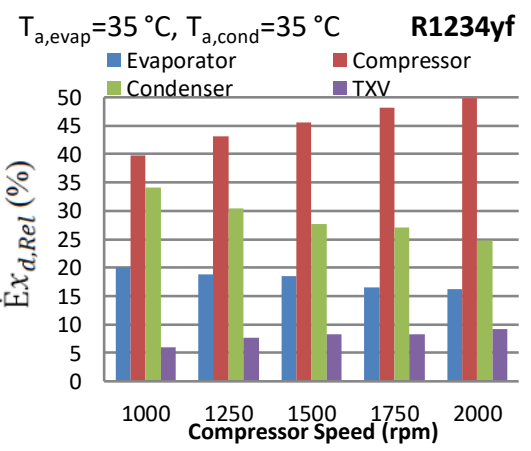

(b)

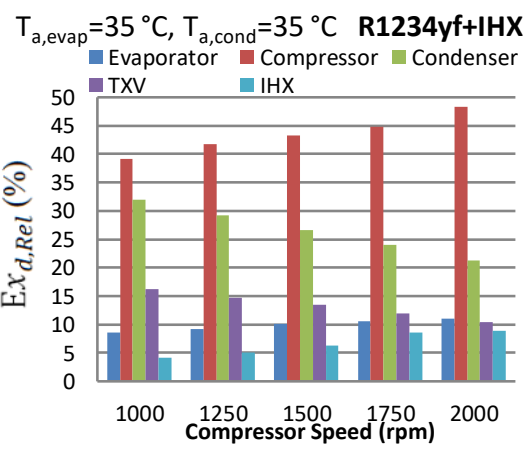

(c)

Figure 4. Exergy destruction of each component against compressor speed at the air stream temperature $35^{\circ} \mathrm{C}$ for (a) R134a, (b) R1234yf, (c) R1234yf+IHX.

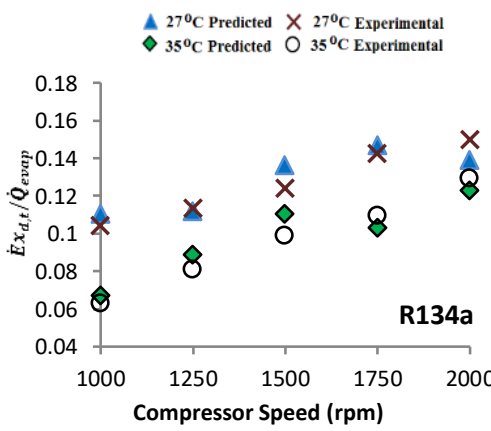

(a)

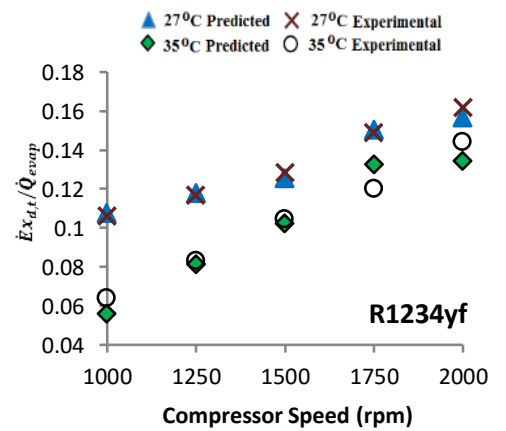

(b)

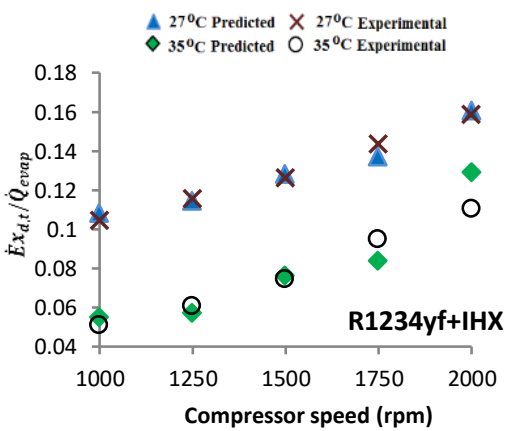

(c)

Figure 5. Total exergy destruction per cooling capacity against compressor speed at different air stream temperatures.

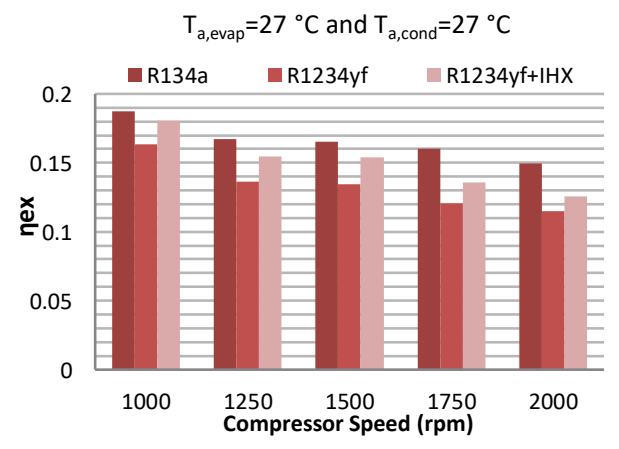

(a)

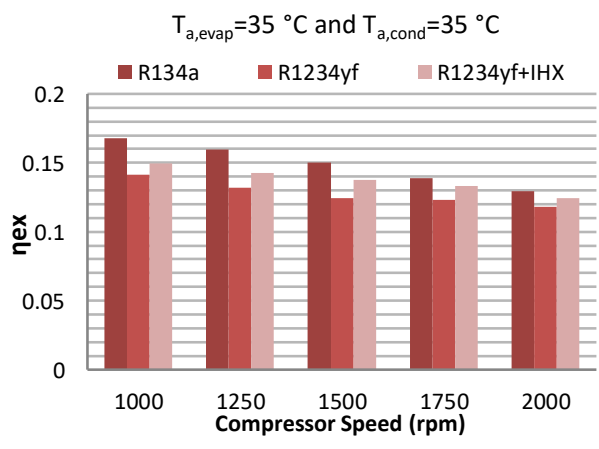

(b)

Figure 6. Exergy efficiency against compressor speed at different air stream temperatures. 
On the other hand, that ratio increases with increasing air stream temperatures at the inlet of the evaporator and condenser, as seen in Fig. 4b. When the AAC system works with R1234yf, this ratio has the highest value because it has been relatively small cooling capacity values in comparison with R134a and R1234yf+IHX. As a result, R1234yf has the highest total exergy destruction per cooling capacity values for all compressor speeds. It has to be noted that the IHX significantly enhanced the performance of the system with causing smaller exergy destruction values regarding to per cooling capacity.

Figure 6 represents the variation of exergy efficiency of the system with respect to the compressor speed.

It is understood from the figure that the exergy efficiency for all conditions yields a decrease due to an increasing exergy destruction value with increasing compressor speed. Despite the fact that the R134a has the highest exergy destruction for all compressor speeds, it has the highest exergy efficiency for all experimental conditions.

\section{Conclusions}

The analysis of an automotive air conditioning (AAC) system was carried out. For this purpose, an exergetic analysis was conducted to determine the place and the amounts of the irreversibilities and then to reduce the thermodynamic inefficiencies within the system. An internal heat exchanger was used in order to provide a performance enhancement to the system. The investigation of the system was performed by using two different refrigerants namely R134a and R1234yf. The influence of the IHX was determined with the refrigerant R1234yf at various compressor speeds, ranging from $1000 \mathrm{rpm}$ to $2000 \mathrm{rpm}$, and fixed $27^{\circ} \mathrm{C}$ or $35^{\circ} \mathrm{C}$ air stream temperatures at the condenser and evaporator inlets. Some concluding remarks concerning the exergetic analysis can be made as follows.

- The highest exergy destruction was determined with $\mathrm{R} 134 \mathrm{a}$ regardless of the air stream temperatures.

- The biggest exergy destruction occurred in the compressor for all operating conditions.

- The total exergy destruction for R1234yf was reasonably enhanced by adapting an IHX to the system.

- The IHX caused a considerable reduction of exergy destruction in the evaporator, although the opposite effect was observed for the condenser.

- The biggest exergy destruction per cooling capacity was calculated for $\mathrm{R} 134 \mathrm{a}$ regardless of the compressor speed and air stream temperature.

- The temperature rise in the air stream caused a decrease in the exergetic performance. Conversely, it increased the total exergy destruction of the system.

In conclusion, an experimental setup was used in order to investigate an alternative refrigerant to the R134a. The refrigerant R1234yf was selected and tested without any modification in the AAC system. The real performance of the system was achieved via using the exergy method. The results of this study may be used for practical analysis and design of similar systems.

\section{Acknowledgements}

The authors would like to thank the University of Yalova for supporting this study through a Research Project No: 2015/BAP/123

\section{Nomenclature}

$A A C \quad$ Automobile air conditioning

$\begin{array}{ll}C & \text { Constant } \\ C O P & \text { Coefficient of performance } \\ \dot{E} x & \text { Exergy destruction, } \mathrm{kW} \\ e_{x} & \text { Flow specific exergy, } \mathrm{kJ} / \mathrm{kg} \\ G W P & \text { Global warming potential } \\ h & \text { Specific enthalpy, } \mathrm{kJ} / \mathrm{kg} \\ I H X & \text { Internal heat exchanger } \\ \dot{m} & \text { Mass flow rate, } \mathrm{kg} / \mathrm{s} \\ M A C & \text { Mobile air conditioning } \\ \dot{Q} & \text { Heat transfer rate, } \mathrm{kW} \\ S & \text { Specific entropy, } \mathrm{kJ} / \mathrm{kg} . \mathrm{K} \\ T & \text { Temperature, K } \\ T X V & \text { Thermostatic expansion valve } \\ \dot{W} & \text { Work, } \mathrm{kW}\end{array}$

Greek Letters

$\eta \quad$ Efficiency

$\begin{array}{ll}\text { Subscripts } \\ c & \text { Component } \\ \text { co } & \text { Condensation } \\ \text { comp } & \text { Compressor } \\ \text { cond } & \text { Condenser } \\ C V & \text { Control volume } \\ d & \text { Destruction } \\ e & \text { Evaporation } \\ \text { evap } & \text { Evaporator } \\ \text { ex } & \text { Exergy } \\ g & \text { Gain } \\ i & \text { Inlet } \\ o & \text { Outlet } \\ p & \text { Pay } \\ r e l & \text { Relative } \\ t & \text { Total } \\ o & \text { Dead state }\end{array}$

\section{References:}

[1] R. Akasaka, K. Tanaka, Y. Higashi, "Thermodynamic Property Modelling for 2,3,3,3-tetrafluoropropene (HFO-1234yf)," International Journal of Refrigeration, 33, 52-60, 2010.

[2] European Parliament and of the Council Official Journal of the European Union, "Emissions from Air Conditioning Systems in Motor Vehicles," Directive No.2006/40/EC, EU, Brussels, 2006.

[3] European Parliament and of the Council, Regulation Official Journal of the European Union, "Fluorinated greenhouse gases," Directive No.2014/517/EU, EU, Strasbourg, 2014.

[4] M. Spatz, and B. Minor, "HFO-1234yf Low-GWP Refrigerant Update," in Proceedings of the International Refrigeration and Air Conditioning Conference, West Lafayette, Indiana, pp. 1-8, 2008.

[5] M. O. McLinden, A. F. Kazakov, J. S. Brown, P. A. Domanski, "A Thermodynamic Analysis of Refrigerants: Possibilities and Tradeoffs for Low-GWP Refrigerants," International Journal of Refrigeration, 38, 80-92, 2014.

[6] C. Zilio, J. S. Brown, G. Schiochet, A. Cavallini, "The Refrigerant R1234yf in Air Conditioning Systems," Energy, 36, 6110-6120, 2011. 
[7] S. Petitjean, and J. Benouali, "R-1234yf Validation \& A/C System Energy Efficiency Improvements," in Proceedings of the SAE Alternate Refrigerant Symposium, Scottsdale, Arizona, 2010.

[8] Y. Lee, D. Jung, “A Brief Performance Comparison of R1234yf and R134a in a Bench Tester for Automobile Applications," Applied Thermal Engineering, 35, 240$242,2012$.

[9] J. Navarro-Esbri, J. M. Mendoza-Miranda, A. MotaBabiloni, A. Barragan-Cervera, J. M. Belman-Flores, "Experimental Analysis of R1234yf as a Drop-in Replacement for R134a in a Vapor Compression System," International Journal of Refrigeration, 36, 870-880, 2013.

[10] D. Sanchez, R. Cabello, R. Llopis, I. Aruzaro, J. Catalan Gil, E. Torrella, "Energy Performance Evaluation of R1234yf，R1234ze(E)，R600a，R290, and R152a as Low-GWP R134a Alternatives," International Journal of Refrigeration, 74, 269-282, 2017.

[11] H. S. Hamut, I. Dincer, G. F. Naterer, "Exergetic and Energetic Evaluations of Hybrid Electric Vehicle Thermal Management Systems," International Journal of Exergy, 12, 341-363, 2014.

[12] J. Navarro-Esbri, F. Moles, A. Barragan-Cervera, "Experimental Analysis of the Internal Heat Exchanger Influence on a Vapour Compression System Performance Working with R1234yf as a Drop-in Replacement for R134a," Applied Thermal Engineering, 59, 153-161, 2013.

[13] H. Cho, H. Lee, C. Park, "Performance Characteristics of an Automobile Air Conditioning System with Internal Heat Exchanger Using Refrigerant R1234yf," Applied Thermal Engineering, 61, 563-569, 2013.

[14] G. Pottker, P. S. Hrnjak, "Experimental Investigation of the Effect of Condenser Subcooling in R134a and R1234yf Air Conditioning Systems with and without Internal Heat Exchanger," International Journal of Refrigeration, 50, 104-113, 2015.Mehmet

[15] M. Direk, A. Kelesoglu, A. Akın, "Theoretical Performance Analysis of an R1234yf Refrigeration Cycle Based on the Effectiveness of Internal Heat Exchanger," Hittite Journal of Science and Engineering, 4, 23-30, 2017.

[16] T. Morosuk, G. Tsatsaronis, "Advanced Exergetic Evaluation of Refrigeration Machines Using Different Working Fluids," Energy, 34, 2248-2258, 2009.

[17] A. Yataganbaba, A. Kilicarslan, I. Kurtbas, "Irreversibility Analysis of a Two-Evaporator Vapor Compression Refrigeration System," International Journal of Exergy, 18, 340-355, 2015.

[18] A. G. Devecioglu, V. Oruc, “The Influence of PlateType Heat Exchanger on Energy Efficiency and Environmental Effects of the Air-Conditioners Using R453A as a Substitute for R22," Applied Thermal Engineering, 112, 1364-1372, 2017.

[19] E. B. Ratts, J. S. Brown, "Experimental Analysis of Cycling in an Automotive Air Conditioning System," Applied Thermal Engineering, 20, 1039-1058, 2000.
[20] A. Yataganbaba, A. Kilicarslan, I. Kurtbas, "Exergy Analysis of R1234yf and R1234ze as R134a Replacements in a Two Evaporator Vapour Compression Refrigeration System," International Journal of Refrigeration, 60, 26-37, 2015.

[21] S. Golzari, A. Kasaeian, S. Daviran, O. Mahian, S. Wongwises, A. Z. Sahin, "Second Law Analysis of an Automotive Air Conditioning System Using HFO1234yf, an Environmentally Friendly Refrigerant," International Journal of Refrigeration, 73, 134-143, 2017.

[22] M. Suhermanto, M. Hosoz, M. C. Aral, "Effect of Ambient Temperature on the Performance Characteristics of Automotive Air Conditioning System Using R1234yf and R134a: Energy and Exergy-based approaches," in Proceedings of the Mechanical Engineering and Engineering Education Conference, Malang, pp. 1-8, 2016.

[23] H. Cho, C. Park, "Experimental Investigation of Performance and Exergy Analysis of Automotive Air Conditioning Systems Using Refrigerant R1234yf at Various Compressor Speeds," Applied Thermal Engineering, 101, 30-37, 2016.

[24] V. Pérez-García, J. M. Belman-Flores, J.L. RodríguezMuñoz, V.H. Rangel-Hernández, A. Gallegos-Muñoz, "Second Law Analysis of a Mobile Air Conditioning System with Internal Heat Exchanger Using Low GWP Refrigerants," Entropy, 19, 175, 2017

[25] M. Direk, A. Kelesoglu, A. Akin, "Drop-in Performance Analysis and Effect of IHX for an Automotive Air Conditioning System with R1234yf as a Replacement of R134a," Strojniški vestnik - Journal of Mechanical Engineering, 63, 314-319, 2017.

[26] M. Direk, A. Kelesoglu, "Performance Analysis of Automotive Air Conditioning System with an Internal Heat Exchanger Using R1234yf under Different Evaporation and Condensation Temperatures," Thermal Science, 2017, Doi: 10.2298/Tsci170125215d

[27] Z. Qi, "Quick and Empirical Correlations for Refrigerant Pressure Drop in Mobile Air Conditioning System Evaporators," International Journal of Refrigeration, 55, 30-36, 2015.

[28] M. C. Aral, M. Hosoz, M. Suhermanto, "Empirical Correlations for the Performance of an Automotive Air Conditioning System Using R1234yf and R134a," Journal of Thermal Sciences and Technology, 37, 127$137,2017$.

[29] A. Bejan G. Tsatsaronis, M. Moran, "Thermal design and optimization”. 1st ed. USA: John Wiley and Sons; 1996.

[30] G. Tsatsaronis, F. Cziesla “Thermoeconomics", In: R.A Meyers, editor. Encyclopedia of physical science and technology, energy. 3rd ed. Academic Press; 2002

[31] M. S. Mert, Ö. F. Dilmac, S. Ozkan, F. Karaca E. Bolat, "Exergoeconomic Analysis of a Cogeneration Plant in an Iron and Steel Factory," Energy, 46, 78-84, 2012.

[32] W. F. Stoecker, J. W. Jones, Refrigeration and Air Conditioning, $2^{\text {nd }} E d$. New York: McGraw-Hill, 1982. 